\title{
COLORADOSCHOOLOFMINES
}

EARTH•ENERGY•ENVIRONMENT

DIVISION OF ECONOMICS AND BUSINESS

WORKING PAPER SERIES

\section{A Simple Mineral Market Model: Can it produce Super Cycles in prices?}

John T. Cuddington

Abdel M. Zellou

\author{
Working Paper 2012-05 \\ http: //econbus.mines . edu/working-papers/wp201205.pdf \\ Colorado School of Mines \\ Division of Economics and Business \\ 1500 Illinois Street \\ Golden, CO 80401
}

July 2012

(c) 2012 by the listed authors. All rights reserved. 
Colorado School of Mines

Division of Economics and Business

Working Paper No. 2012-05

July 2012

Title:

A Simple Mineral Market Model:

Can it produce Super Cycles in prices?*

Author(s):

John T. Cuddington

W.J. Coulter Professor of Mineral Economics

Division of Economics and Business

Colorado School of Mines

Golden, CO 80401-1887

jcudding@mines .edu

Abdel M. Zellou

Division of Economics and Business

Colorado School of Mines

Golden, CO 80401-1887

abdel.zellou@gmail.com

\begin{abstract}
This paper develops a stylized supply-demand model for a mineral / nonrenewable commodity. It embodies important distinctions between short-run and long-run mineral supply and the derived demand for minerals as intermediate goods in production sectors with differing intensities of use. This framework is used to address the question: under what conditions might one expect to observe super cycles (i.e. cycles with a period of 2070 years) in minerals prices? A plausible time path for GDP growth and the structural transformation that accompanies economic development in an emerging region is specified. Using these drivers and reasonable supply and demand parameters, price dynamics are simulated. The result is an asymmetric price cycle with a peak price that is about $250 \%$ above trend and an expansion phase that lasts for about 20 years. Thus, this simple model is capable of producing a single cycle with a frequency and amplitude in the range estimated in the empirical literature on super cycles. As other regions reach the development 'take-off' phase, additional super cycles should emerge.
\end{abstract}

Keywords: Super Cycles, Long Cycles, Metal Markets, Metals Intensity of Use

JEL Classification: E32, E22, E37.

\footnotetext{
${ }^{*}$ We would like to thank John Tilton and an anonymous referee for helpful comments. We also thank participants in the graduate research seminar at Colorado School of Mines, especially Daniel Kaffine and Edward Balistreri.
} 


\title{
A SIMPLE MINERAL MARKET MODEL: CAN IT PRODUCE SUPER CYCLES IN PRICES?
}

7-18-2012 version

\begin{abstract}
This paper develops a stylized supply-demand model for a mineral / nonrenewable commodity. It embodies important distinctions between short-run and long-run mineral supply and the derived demand for minerals as intermediate goods in production sectors with differing intensities of use. This framework is used to address the question: under what conditions might one expect to observe super cycles (i.e. cycles with a period of 20-70 years) in minerals prices? A plausible time path for GDP growth and the structural transformation that accompanies economic development in an emerging region is specified. Using these drivers and reasonable supply and demand parameters, price dynamics are simulated. The result is an asymmetric price cycle with a peak price that is about $250 \%$ above trend and an expansion phase that lasts for about 20 years. Thus, this simple model is capable of producing a single cycle with a frequency and amplitude in the range estimated in the empirical literature on super cycles. As other regions reach the development 'take-off' phase, additional super cycles should emerge.
\end{abstract}

JEL codes: E32 (Business Fluctuations, Cycles), E22 (Capital, Investment, Capacity), E37

(Forecasting and Simulation: Models and Applications)

Key words: Super Cycles, Long Cycles, Metal Markets, Metals’ Intensity of Use 


\section{Motivation}

This paper has two related objectives. The first is to develop a stylized supply-demand model for a mineral commodity that embodies (i) important distinctions between short-run and long-run mineral supply and (ii) the derived demand for minerals as intermediate goods in production sectors with differing intensities of use. The second objective is to use this framework to address the question: under what conditions might one expect to observe so-called 'super cycles' in mineral prices in response to the industrialization and urbanization of a major regional block in the global economy? In the literature (Heap 2005; Cuddington and Jerrett 2008; Jerrett and Cuddington 2008; Jerrett 2010), super cycles are defined as long cycles having a period between 20 and 70 years (including both the expansion and contraction phases), much longer than business cycle periodicity of, say, 2-8 years.

There has been a renewed interest in long-run trends in real mineral prices since the late 1990s, as real prices have risen sharply. Many analysts claim that the current sustained rise in prices (albeit with considerable year-to-year volatility) reflects a long-term super cycle associated with the rapid industrialization and urbanization in the $B R I C^{1}$ countries, especially China (Rogers 2004; Heap 2005). Moreover, earlier super cycle episodes appear to match the timing of rapid industrialization in Western Europe, the United States, and the Japanese renaissance of the post-World War II period.

Many economists, however, have a longstanding skepticism about the presence of longerrun cycles, arguing that they may be a statistical artifact caused by inappropriate detrending methods (Adelman 1965). Cuddington and various coauthors have attempted to measure super

\footnotetext{
${ }^{1}$ The BRIC countries are Brazil, Russia, India and China.
} 
cycles in real mineral ${ }^{2}$ prices using modern band-pass filtering techniques. These techniques tend to identify super cycles with a timing that supports the super cycle hypothesis regarding industrialization and urbanization of major economies (Cuddington and Jerrett 2008; Jerrett and Cuddington 2008; Jerrett 2010; Zellou and Cuddington 2012). Figures 1-2 display the real prices, the super cycles and the trend components for oil and metals.

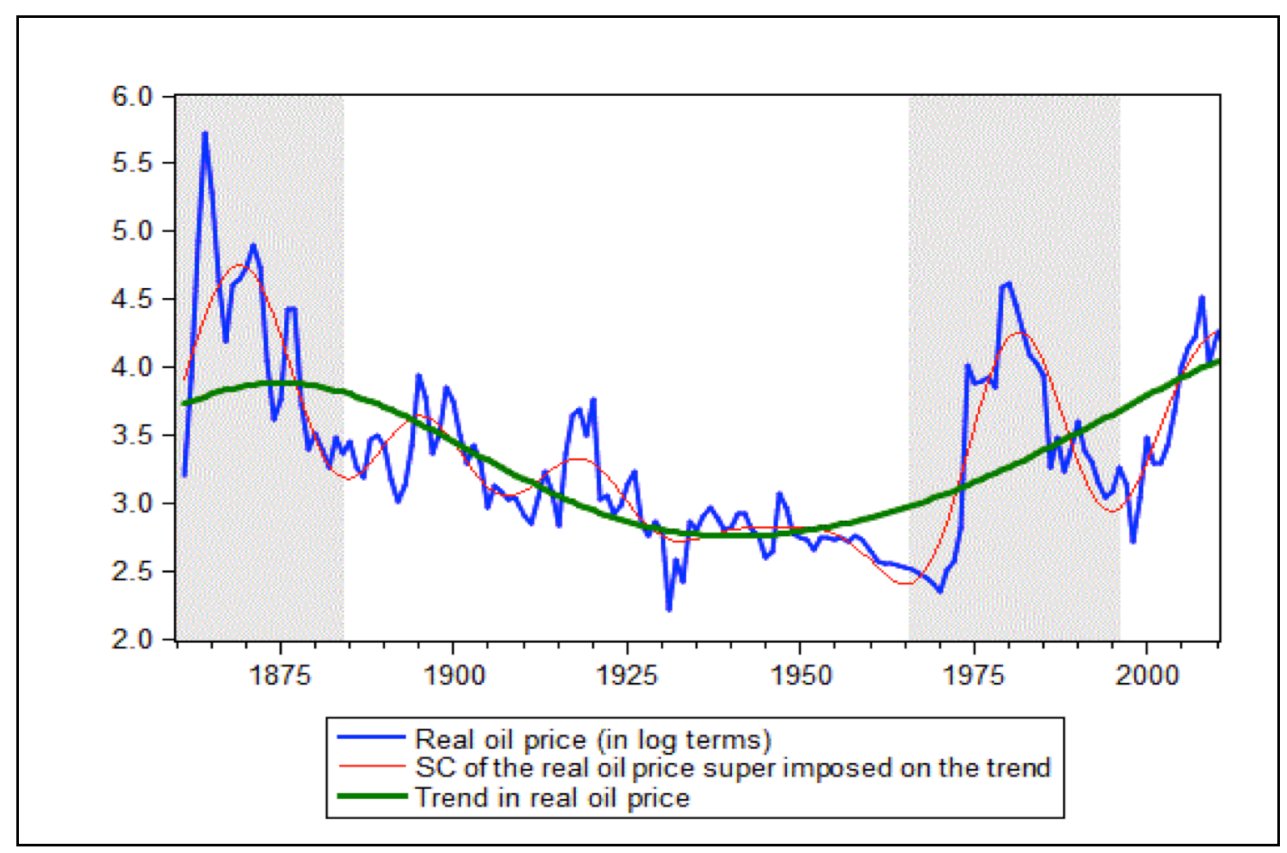

Figure 1: Real price of oil (in logs) with trend and SCs overlaid on the trend component. The latter equals Trend $+S C$, so the difference between the two lines is the SC component shown below in Figure 2. The real price of oil is computed using the U.S. CPI as a price deflator (2005 $=100$ ). See Cuddington and Jerrett (2008) for a description of the statistical technique used to generate the super cycle and trend components.

In spite of the trend-cycle decomposition exercises, considerable skepticism about the presence of super cycles in mineral prices remains -- especially given the sharp pull back in prices in late 2008 and early 2009. At the conceptual level, Radetzki et al (2008) emphasize that the demand expansion associated with industrialization and urbanization may or may not lead to sustained increases in mineral prices, depending on the rapidity of the mineral supply response to

\footnotetext{
${ }^{2}$ Throughout this paper, minerals refer to both metals and energy commodities.
} 
changes in demand. In particular, rapid anticipatory increases in mineral production capacity in response to the expectation of sustained increases in future demand would prevent prices from exceeding marginal costs for decades at a time. This would prevent super cycles from occurring.

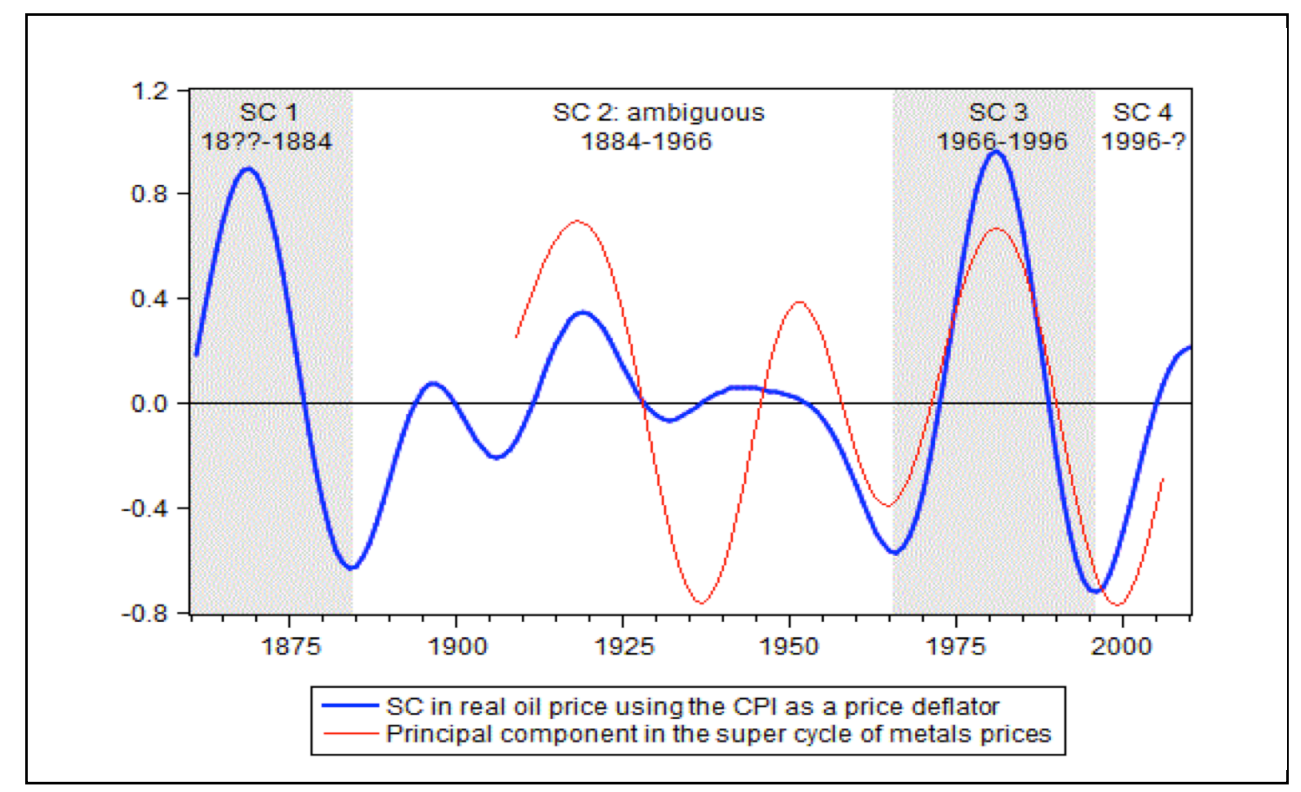

Figure 2: Super cycles in real oil prices and in metals prices. The units on the vertical axis represent percentage deviations from trend. For example, +0.40 indicates price $40 \%$ above the long-term trend. The shading corresponds to the super cycles in real oil prices with the corresponding dates (from trough to trough). Four different epochs are identified in ZellouCuddington (2012). There appears to be three obvious SCs in oil prices, the first one between 1861 (or earlier) and 1884, and the last two after 1966 to date. The period 1884-1966 is harder to interpret and has been aggregated into one $\mathrm{SC}$, but it might better be interpreted as an ambiguous or inconclusive period. Note the similarity of metals and crude oil super cycles after WWII. Source: Cuddington and Jerrett (2008) on metals and Zellou and Cuddington (2012) on crude oil.

The simple mineral supply-demand model described in this paper captures the issues typically involved when discussing the plausibility of the super cycle hypothesis. Here's a 'bird's eye' view of what is formalized in the model that follows. Consider the typical characterization of mineral supply as being very price inelastic in the short run $(S R)$ due to capacity constraints but very price elastic in the long run $(L R)$, as shown in Figure 3. ${ }^{3}$ Demand depends on the real

\footnotetext{
${ }^{3}$ For empirical evidence on short-run and long-run price elasticities of energy demand and supply, see the extensive
} 
price of minerals and a broad measure of economic activity that captures the level and composition of global GDP. A sustained increase in demand for resources during the industrialization and urbanization of a large region in the global economy is represented by a demand curve shift from $D_{0}$ towards $D_{1}$. (More generally, the demand curve would be shifting rightward more rapidly than it would have in the absence of rapid economic development.) The shift in demand along the short-run supply curve will cause mineral prices to rise sharply. The higher prices will, in turn, induce expansion in productive capacity, thereby pulling prices back towards pre-boom levels. If there is a later deceleration in demand, this process will reverse itself, with mineral prices temporarily falling below $L R$ marginal cost $(M C){ }^{4}$ The key issues for determining price dynamics are the magnitude and duration of the demand shift and the speed of supply adjustment as the mineral market moves from $S R$ to $L R$ equilibrium. Presumably a stochastic sequence of development episodes in different parts of the world produces a series of super cycles. ${ }^{5}$ (Appendix $\mathbf{C}$ extends the model in the text to two regional development episodes, producing two super cycles.)

Section 2 provides a simple mineral market model that can be used to analyze the dynamic effects of growth and structural transformation on mineral prices and to ask whether

writings of Carol Dahl (e.g. Dahl (1994) and Dahl and Duggan (1996)) or Krichene (2002). For the copper market, see the classic paper by Fisher, Cootner, and Baily (1972, p.568): "The copper market is found to be characterized by low short-run but very high long-run price elasticities, making for considerable sensitivity to exogenous forces."

${ }^{4}$ Firms will continue to operate in the short run as long as price exceeds their variable costs.

${ }^{5}$ We would not expect the emergence economies to occur in a deterministic sequential ('regular') way. Indeed, when macroeconomists study business cycles, they stress that these cycles are neither regular nor symmetric; we'd expect the same for super cycles. The band pass filtering technique used to extract cycles, be they business cycles or super cycles, presumes the cycles are stochastic (irregular), not regular waves like sine or cosine functions. The empirical super cycles identified in the Cuddington-Jerrett (2008), Jerrett-Cuddington (2008) and ZellouCuddington (2012) papers are not regular, but vary in amplitude, frequency, and asymmetry. 
super cycles are likely to occur. ${ }^{6}$ Section 3 reports various simulation exercises to get a sense of the model's characteristics and their implications. The first simulation considers the dynamic effects of a positive one-time (permanent) shift in the level of demand. It shows how the speed of capacity adjustment and the short-run price elasticity of demand affect the time needed for the supply capacity and price to reach the new equilibrium. The model is calibrated to match common belief that is takes about five to seven years to bring marginal supply on stream. ${ }^{7}$ The second simulation considers a gradual transition in the real GDP growth rate from zero to two percent (rather than a level shift), with structural transformation that typically accompanies growth. Other supporting simulations are presented in Appendix B. The simulation results suggest that (with, at least, some constellations of parameter values) the onset of modern economic growth with the industrialization and urbanization that entails - can produce super cycle behavior in our mineral market model. Growth without structural transformation, on the other hand, does not produce super cycles in mineral prices, as Appendix B shows. Finally, Section 4 provides concluding remarks.

\footnotetext{
${ }^{6}$ We think it is a virtue that the model is 'simple,' but there are many considerations that it ignores. It is certainly not a multi-sectoral dynamic general equilibrium of a global economy undergoing structural transformation. Indeed the modeling of structural transformation in micro-foundations models of economic development is in its infancy; see Acemoglu (2009, Ch.20).

${ }^{7}$ Radetzki et al (2008, p. 125) note: "Clearly, in the absence of a broad economic slowdown, commodity booms might well continue for more than one or two years, as expansions to existing installations typically take at least that much time, while 5 years or so are needed to build new greenfield capacity (Tilton, 2006a,b; Radetzki, 2008)." They go on to provide a number of reasons why adjustment lags may be much longer (See Radetzki et al (2008, p. 126ff). Their numerical simulations suggest that "an investment cycle of more than 5 years though probably less than 15 years is needed to bring markets and prices back to long-run equilibrium." (p.126) Cuddington and Jerrett (2008) argue that the time needed to bring large amounts of additional capacity online may be considerably longer than five years in the current market and regulatory environment.
} 


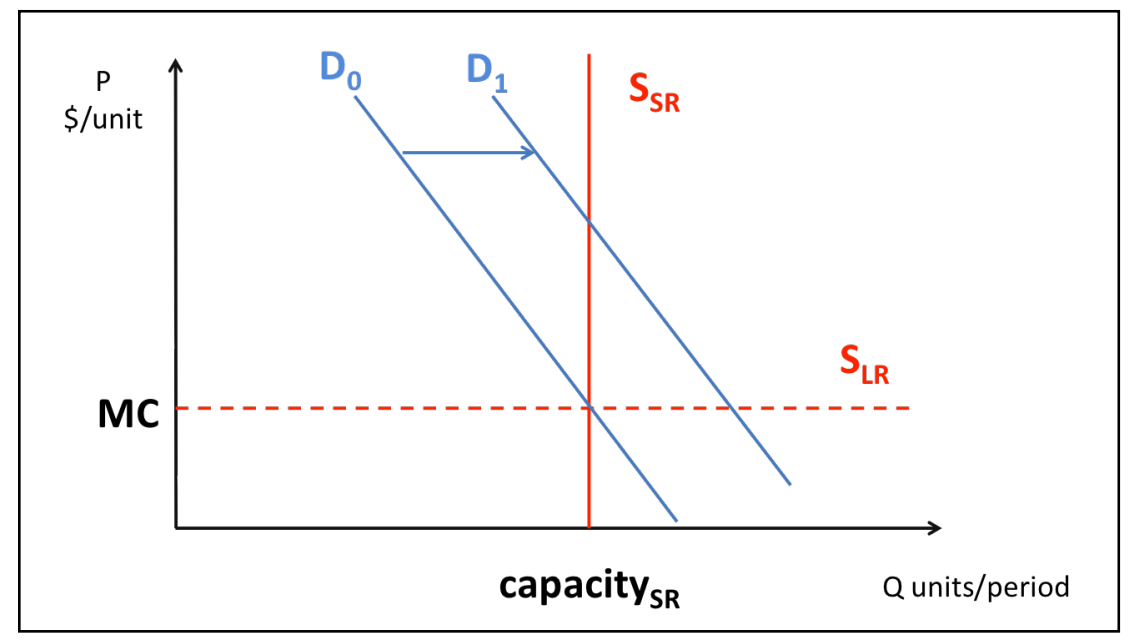

Figure 3: Supply and demand in the resource market. $\mathrm{D}_{0}$ represents the initial demand. $\mathrm{D}_{1}$ simulates the shift in demand as described in the different scenarios. $\mathrm{S}_{\mathrm{SR}}$ is the short run supply curve and $\mathrm{S}_{\mathrm{LR}}$ is the long-run supply curve. At each price, there is a higher quantity demanded as income and intensity of use (IOU) rise.

\section{A Simple Mineral Market Model}

Our objective in the remainder of this paper is to formalize the key determinants of global mineral supply and demand in a simple analytical model and then analyze their implications via model simulation. Global demand for the mineral resource is assumed to depend negatively on the real price of the resource $\left(P_{R}\right)$, positively on the overall mineral intensity of use of the economy ( $I O U$ ), and positively on a measure of aggregate economic activity ( $A E A)$. The latter, in turn, depends on the level of the population (POP) and per capita income $(y)$. Thus, the mineral demand curve shifts over time due to population growth, the growth rate in real $G D P$ per capita, and the evolution of the resource intensity of use ( $I O U$ ) due to structural transformation of the economy. On the mineral supply side, the key determinants are short-run capacity constraints, and expected future mineral prices relative to long-run marginal production costs (which is interpreted as including user cost of nonrenewable resources). The latter affect long-run capital investment decisions and hence future productive capacity. Thus our model embodies the typical assumption by mineral economists that supply is inelastic at capacity in the 
short run and highly elastic in the long run. The speed at which supply capacity expands when expected future price exceeds long-run marginal costs depends on the speed of adjustment parameter.

Although this simple analytical model could be used to answer a number of questions regarding mineral markets, we focus on whether - or under what circumstances -- our model can produce a super cycle in mineral prices, i.e. a long price upswing lasting 10-30 years. To address this question, we assign reasonable model parameter values and simulate the effects on mineral prices of a transition from Malthusian stagnation (with zero trend GDP growth) to a period of modern economic growth -- with the structural transformation that growth and economic development entails. That is, we specify a particular time path for the economic activity variable on the demand side of the model, then simulate its implications for supply response and hence prices over time.

The simple analytical model incorporates the following ingredients, which our experimentation suggests are necessary (or at least sufficient) in a supply-demand equilibrium model to generate a super cycle: (1) an acceleration in economic growth, (2) the structural transformation (industrialization and urbanization) that accompanies that growth, (3) a manufacturing sector that is resource intensive relative to the agriculture and service sectors, (4) a short-run mineral supply that is highly price inelastic in the short run relative to the long run, and (5) expansion of productive capacity in the mineral sector that occurs rather gradually over time as long as expected future prices exceed long-run marginal costs. A description of each of these ingredients follows. 
Ingredient \#1: An Acceleration in Economic Growth

Oded Galor's (2011) Unified Growth Theory seeks to explain century after century of stagnation followed by a gradual transition to the era of modern economic growth by different regions at different times. Several key nations in Western Europe and the 'Western European offshoots $^{8}$ (US, Canada, Australia and New Zealand) have already evolved through three broad development phases: the Malthusian Epoch, the Post-Malthusian Regime, and the Modern Growth Regime. The Malthusian Epoch, which runs up to roughly 1750 for the abovementioned 'development leaders,' is a period of no (trend) growth in per capita incomes. During the Malthusian Epoch, any temporary improvements in living standards caused by technological progress or land expansion were ultimately nullified by rising birth rates, so per capita incomes fluctuated around the subsistence level for centuries.

The Post-Malthusian Regime, which for the growth leaders spanned the 1750-1870 period, is the transition period where per capita incomes began to rise slowly, due to the acceleration in technological progress that higher population densities engendered. The Modern Growth Regime witnessed further acceleration in technological progress, a shift in incentives for investment in education, and ultimately a demographic transition due to lower birth and death rates. With the decline in population growth, technological improvements translated more effectively into rising standards of living, with real per capita GDP experiencing trend growth of perhaps two percent per year.

To summarize the transition from Malthusian stagnation to the epoch of modern economic growth, we assume that there is a long-run evolution in the real GDP per capita from zero to two percent, as shown in Figure 4. For simplicity, all issues involving the size and

\footnotetext{
${ }^{8}$ See Maddison (2009).
} 
composition of the population are ignored by assuming the population is constant over time. (Incorporating these considerations would make the surge in economic activity in our model larger, thereby increasing the likelihood of producing super cycles.)

The assumed time path for per capita real GDP in Figure $\mathbf{4}$ was generated using a simple logistic function. See Appendix A for a more complete description of the logistic function, which is used at several points in the paper to produce smooth transition paths. Note that our model takes the transition path for real economic growth as exogenously given, and focuses on its implications for mineral demand. See Galor's (2011) book for a summary of pathbreaking research by Galor and others to explain how some (but not yet all) countries have emerged from Malthusian stagnation to a modern epoch with sustained economic growth and rising living standards.

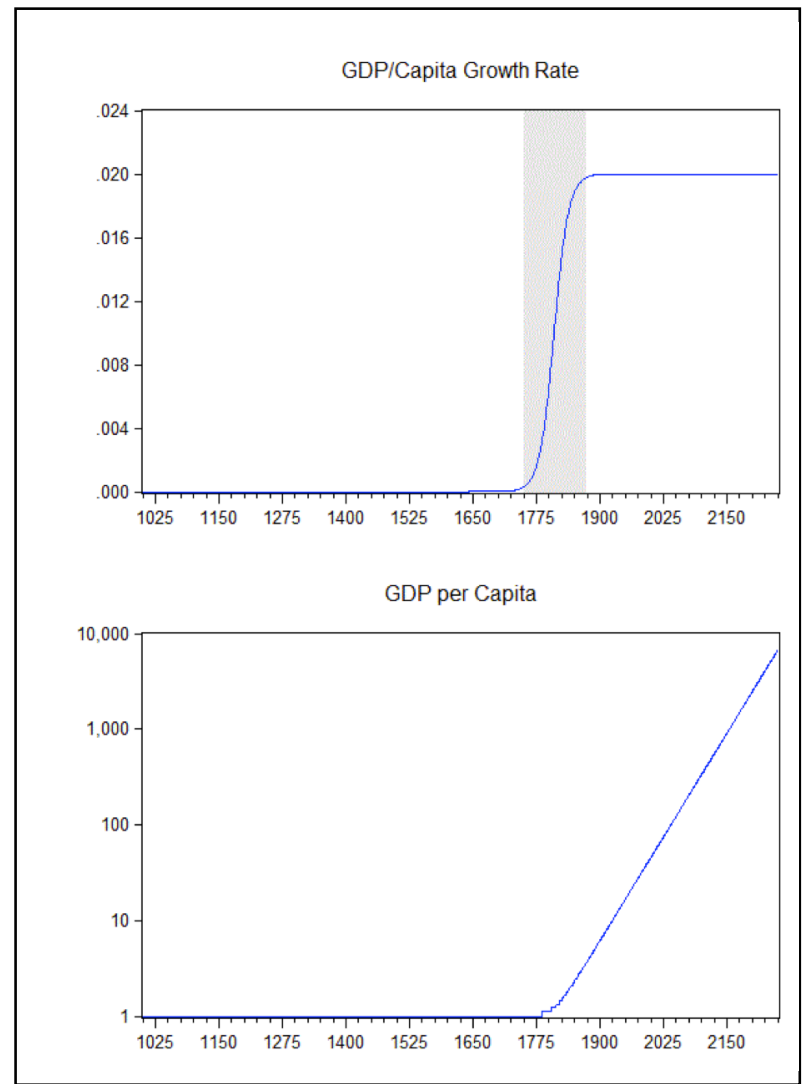

Figure 4: GDP per capita growth rate (top panel) and GDP per capita on log scale (bottom panel). 
Ingredient \#2: Structural Transformations (Industrialization and Urbanization)

With economic growth and economic development comes structural transformation of the economy. ${ }^{9}$ A key aspect of the economic development process that we wish to capture is the evolution in final demand shares of agriculture, manufacturing (including construction) and services, $A, M$ and $S$ respectively, as per capita income rises. For poor countries, the agricultural share of total expenditure dominates. As per capita incomes rise, however, the share of household expenditure on agricultural products gradually declines (Engel's Law), and the expenditure share on manufacturing goods rises. As per capita incomes rise further, the expenditure share on services begins to rise, which ultimately reduces both the agricultural and manufacturing goods expenditure shares. These stylized facts are referred to as the 'Kuznets facts' and are summarized in Figure 5 taken from Acemoglu (2009). ${ }^{10}$

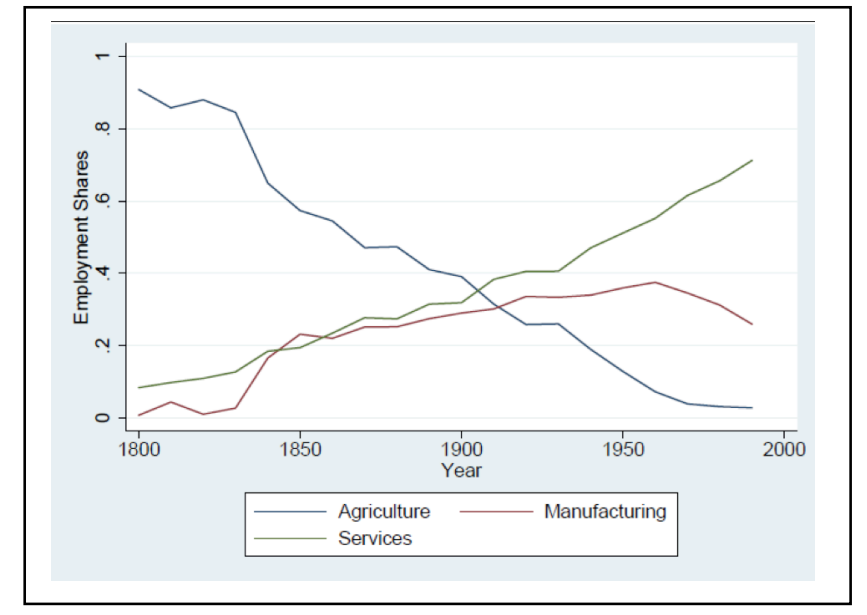

Figure 5: The Kuznets Facts (Source: Acemoglu 2009)

\footnotetext{
${ }^{9}$ There is also a demographic transition that we ignore in this initial model. Galor (2011) provides a detailed discussion on the causes of changes in fertility and mortality rates during the development process.

${ }^{10}$ Note that Figure 5 reports on employment shares. Presumably a similar pattern occurs in sectoral output shares in GDP (the composition of supply) and expenditure shares (the composition of demand) at least at the global level (where exports and imports net to zero). In economies with international trade, of course, production shares need not equal expenditure shares. We expect to find the evolution in expenditure shares, but not necessarily production shares, as per capita incomes rise. Production shares will reflect relative factor abundance across countries to a considerable extent (e.g. the oil-rich Middle East countries).
} 
Rather than attempting the technically daunting challenge of finding a non-homothetic utility function that produces the sort of non-linear income expansion path implied by the Kuznets facts, we directly specify a reasonable expenditure system in terms of expenditure shares of the three different sectors: $S_{A}, S_{M}$ and $S_{S}$. The expenditure shares on agricultural goods and services are assumed to be logistic functions of the natural logarithm of per capita income $(\ln y)$, with the manufacturing share being determined by the adding-up constraint:

$$
\begin{aligned}
& S_{A}=S_{A, 0}+\frac{S_{A, T}-S_{A, 0}}{1+e^{\left[-\gamma_{A}\left(\ln y-\ln y_{A}\right)\right]}} \\
& S_{S}=S_{S, 0}+\frac{S_{S, T}-S_{S, 0}}{1+e^{\left[-\gamma_{S}\left(\ln y-\ln y_{S}\right)\right]}} \\
& S_{M}=1-S_{A}-S_{S}
\end{aligned}
$$

To interpret the logistic functions, consider the agricultural share $S_{A}$. Its initial value is $S_{A, 0}$. The specified long-run value is $S_{A, T}$, which may be higher or lower than the initial value depending on whether one wants a rising or falling share over time. The parameter $\gamma_{A}$ affects the speed of adjustment from the initial to the terminal expenditure share. Note that this expenditure system collapses to the simple homothetic Cobb-Douglas case when there is no change in the shares over time; that is, $S_{i, 0}=S_{i, T}$. As in the Cobb-Douglas case (and in contrast to the translog specification, say), all direct price effects on expenditure shares are zero. This specification has the advantage of producing a very tractable expression for the intensity of use below. $^{11}$

\footnotetext{
${ }^{11}$ It obviates the need to explicitly specific all goods and factor market clearing conditions in the model in a general way.
} 
We assume that $\ln y_{A}<\ln y_{S}$ in (0.0) so that the inflection point in the agricultural share comes at a lower level of per capita income (and hence earlier in time) than the inflection point in the service share. Our initial simulations used the following parameter values:

$$
\begin{aligned}
& S_{A 0}=0.90, S_{A, T}-S_{A, 0}=-0.85, \gamma_{A}=16, \ln y_{A}=1.5 \\
& S_{S 0}=0.05, S_{S, T}-S_{S, 0}=+0.75, \gamma_{S}=12, \ln y_{S}=1.7
\end{aligned}
$$

These values produce the expenditure share paths displayed in Figure 6. As the initial income per capita is set to unity ( $\operatorname{so} \ln y_{A 0}=0$ ), the parameter value of $\ln y_{A}=1.5$ implies an increase in per capita income of $150 \%$ to reach the inflection point in the agricultural share. Similarly the inflection point in the service share is at an income $170 \%$ higher that the initial income per capita.

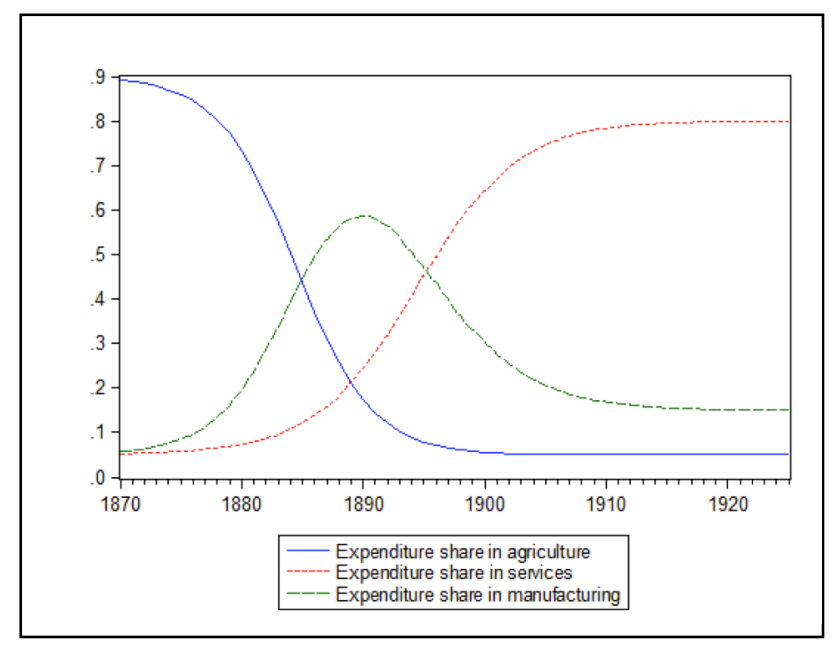

Figure 6: Expenditure shares computed using logistic functions to capture the Kuznets facts

Ingredient \#3: The Manufacturing Sector is Relatively Resource Intensive

In our model economy, mineral demand is a derived demand for its use as an intermediate input in production. Given our interest in studying the effects of the structural transformation that accompanies economic development, three broad productive sectors of the 
economy are considered: agriculture $(A)$, manufactures $(M)$, and services $(S)$. For simplicity, production in each sector uses only labor and resources $(L, R)$ with simple constant returns to scale Cobb-Douglas technology: ${ }^{12}$

$$
\begin{gathered}
Y_{A}=L_{A}^{1-\alpha_{A}} R_{A}^{\alpha_{A}} \\
Y_{M}=L_{M}^{1-\alpha_{M}} R_{M}^{\alpha_{M}} \\
Y_{S}=L_{S}^{1-\alpha_{S}} R_{S}^{\alpha_{S}}
\end{gathered}
$$

Factor intensity is assumed to differ across sectors with the manufacturing sector being relatively resource intensive. Specifically, we assume $\alpha_{M} \gg \alpha_{A}=\alpha_{S}$.

Profit maximization by firms in each sector implies the following resource demand functions: ${ }^{13}$

$$
\begin{aligned}
& R_{A}=\left(\frac{1}{P_{R}}\right) \alpha_{A} * P_{A} * Y_{A} \\
& R_{M}=\left(\frac{1}{P_{R}}\right) \alpha_{M} * P_{M} * Y_{M} \\
& R_{S}=\left(\frac{1}{P_{R}}\right) \alpha_{S} * P_{S} * Y_{S}
\end{aligned}
$$

Total demand for resources $R$ is the summation of derived demands across the three sectors, which is a function of the equilibrium levels of output produced in each sector. Next the determinants of the demands for final goods $(A, M, S)$ are considered.

\footnotetext{
${ }^{12}$ As on the expenditure side, one could consider more general production functions. Our use of Cobb Douglas contributes to the simple, intuitive expression for $I O U$ below.

${ }^{13}$ Cobb-Douglas technology implies that the resource share is constant in each sector with $\alpha_{i}=\frac{P_{R} R_{i}}{P_{i} Y_{i}} \forall i=A, M, S$ even if relative prices change.
} 
In the final goods markets, prices $\left(P_{A}, P_{M}, P_{S}\right)$ are assumed to adjust to equate supply and demand. This implies that expenditure shares of GDP equal output shares:

$$
\begin{aligned}
& S_{A}=P_{A} Y_{A} / P Y \\
& S_{M}=P_{M} Y_{M} / P Y \\
& S_{S}=P_{S} Y_{S} / P Y
\end{aligned}
$$

where

$$
P Y \equiv P_{A} Y_{A}+P_{M} Y_{M}+P_{S} Y_{S}
$$

The resource demand equations in (0.0) and the final goods market equilibrium conditions in $(0.0)$ can now be combined to obtain a tractable and intuitive expression for global mineral demand in terms of final expenditure shares and (mineral) factor intensities of the production sectors:

$$
\begin{aligned}
R^{D} & \equiv R_{A}+R_{M}+R_{S}=\left(\frac{1}{P_{R}}\right) \alpha_{A} * P_{A} * Y_{A}+\left(\frac{1}{P_{R}}\right) \alpha_{M} * P_{M} * Y_{M}+\left(\frac{1}{P_{R}}\right) \alpha_{S} * P_{S} * Y_{S} \\
& =\left(\frac{1}{P_{R}}\right)\left[\alpha_{A} * S_{A}+\alpha_{M} * S_{M}+\alpha_{S} * S_{S}\right] * P^{*} y * P O P
\end{aligned}
$$

The term in square brackets is an expression for the aggregate mineral intensity of use (IOU ) of the economy:

$$
I O U=\alpha_{A} * S_{A}+\alpha_{M} * S_{M}+\alpha_{S} * S_{S}
$$

Figure 7 shows how IOU depends on per capita income, given the parameterization of our model. It has the familiar inverted $\mathrm{U}$ shape discussed in the mineral economics literature. 
See, e.g., Tilton (2003) for a discussion of intensity of use, and Warell and Olson (2009) for an econometric analysis.

The aggregate mineral demand function in (0.0) depends negatively on the real price of mineral resources and positively on: (i) the size of the population ( $P O P$ ), (ii) the level of real $G D P$ per capita ( $y$ ) and (iii) the mineral intensity of $G D P$ ( $I O U$ ). Rewriting (0.0) in loglinear form yields:

$$
\ln \left(R^{D}\right)=\beta_{0}+\varepsilon_{P} * \ln \left(P_{R} / P\right)+\varepsilon_{y} * \ln \left(I O U^{*} y^{*} P O P\right)
$$

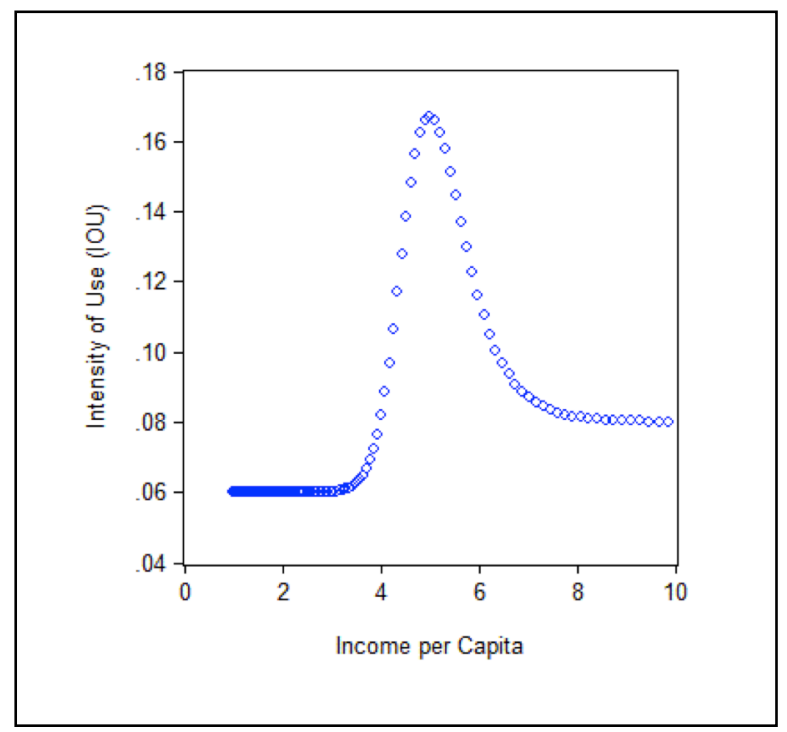

Figure 7: The simulated intensity of use as a function of the income per capita from our model. The inverted U-shape reflects the hypothesis that the intensity of use increases as income per capita increases until reaching a peak, and then decreases as the service sector expands and the intensity of use shrinks.

Our simple assumption that all production functions are Cobb-Douglas implies a price elasticity of mineral demand equal to unity $\left(\varepsilon_{P}=-1.0\right)$. Our initial simulations use this value, but then go 
on to consider an empirically more plausible value $\varepsilon_{P}=-0.2$ to capture the presumption that the price elasticity of mineral demand is very inelastic in the short run. The income elasticity of mineral demand in our model depends on the level of per capita income. What we might call the 'pure' income elasticity --where $I O U$ fixed -- is unity: $\varepsilon_{y}=1.0$. Recall, however, that $I O U$ is a concave function of $y$, as shown in the Figure above. Thus, increases in $y$ have a nonlinear effect on mineral demand with the income elasticity rising and then falling, due to structural changes that accompany income development.

To understand the various simulations below, it will be useful to consider the rate at which the mineral demand curve is shifting over time. This horizontal shift in demand along the SR supply curve (described below), along with the short-run price elasticities of supply and demand, will determine mineral prices at any point in time. The demand shift rate $(D S R)$ is found by taking the (continuously compounded) rate of change in the economy activity term in (1.10):

$$
D S R=\Delta \log (I O U * Y * P O P)=I \hat{O} U+\hat{Y}+P \hat{O} P
$$

It is a summation of the rates of changes in the $I O U(I \hat{O} U)$, income per capita $(\hat{Y})$, and population $(P \hat{O P})$.

Ingredient \#4: The Typical Mineral Supply Curve is Almost Perfectly Price-Inelastic in the Short Run due to Capacity Constraints, but Virtually Perfectly Price Elastic in the Long Run

A typical characterization of mineral supply assumes that the short-run supply curve is highly price elastic at a price equal to the average variable cost up to a capacity constraint, as shown in Figure 3, where the short-run supply curve is price inelastic. (See, e.g., Tilton (2003) or Radetzki (2008) and the references in fn. 3 above.) In the long run, however, supply is highly 
elastic at price equal to long-run average cost. The long-run average cost of mineral production, in principle, rises over time as a result of increases in the user cost of nonrenewable resources due to depletion. On the other hand, technological improvements work in the opposite direction. Our model makes the innocuous assumption that these two long-run forces just offset each other, yielding a horizontal long-run cost curve in the mineral industry. ${ }^{14}$

To capture the short-run price inelasticity, assume that the mineral production function takes the very simple form:

$$
R_{t}^{S}=A K_{t}
$$

where $K$ is the amount of currently available capital (i.e. capacity) in the mineral production sector. Although $K$ is predetermined in each period, it changes over time as a result of new investment in the previous period and ongoing depreciation: ${ }^{15}$

$$
K_{t}=K_{t-1}+I N V_{t-1}-d e p * K_{t-1}=(1-d e p) K_{t-1}+I N V_{t-1}
$$

where $\boldsymbol{d e p}$ is the depreciation rate.

Ingredient \#5: The Expansion of Productive Capacity in the Mineral Sector continues as long as expected future prices exceed long-run marginal cost

\footnotetext{
${ }^{14}$ Empirical analyses of super cycles, on the other hand, do not make this simplistic assumption. Instead they use band pass filters to extract the very long-term component in mineral prices (with a period greater than 70 years), which may rise or fall gradually over various sub-periods. Super cycles are then defined as the cyclical component with a window between 20 and 70 years around the log-term variable trend line.

${ }^{15}$ This typical capital accumulation specification implicitly assumes a 'time to build' of one year. A one-year time to build is unrealistically short for many mining and petroleum projects. Hence, one might consider an n-period to build model, where say $1 / n$ of each period's investment becomes embodied in useable capital over each of the subsequent years and the coefficients on the last n-periods of investment sum to unity
}

$$
K_{t}=K_{t-1}(1-d e p)+\sum_{i=1}^{n} \frac{1}{n} I N V_{t-i}
$$


We assume that gross investment includes replacement of depreciating capital in an economy whose aggregate GDP is growing at rate $g_{t}$ plus net investment, which is a positive function of the expected future profit margin:

$$
I N V_{t}=\left(g_{t}+d e p\right) K_{t}+\lambda\left(\ln P_{R, t}^{e}-\ln M C\right) K_{t}
$$

where $M C$ is the $L R$ marginal cost including the user cost of nonrenewable resources, and $P_{R, t}^{e}$ is the expected future mineral price at time $t$. Our expected future mineral price is assumed to reflect a linear combination of forward-looking and backward-looking behavior: ${ }^{16}$

$$
P_{R, t}^{e}=\gamma P_{R, t-1}+(1-\gamma) P_{R, t+1}
$$

Our simulations put equal weight on the forward and backward-looking terms (i.e. $\gamma=0.5$ ).

Note that (by recursive forward substitution), the entire future time path of mineral prices

impacts current investment, but of course with less and less weight for future periods that are very far off.

The $\lambda$ parameter in the investment equation governs the speed of adjustment from the short run, where the supply curve is vertical, to the long run, where it is horizontal. ${ }^{17}$ Our initial

\footnotetext{
${ }^{16}$ This flexible specification is used to model both inflation and exchange rate expectations in the IMF's FPAS model developed in Berg et al. (2006a,b). The forward looking component is a model-consistent or perfect-foresight solution for the dynamic model in question.

${ }^{17}$ Our investment equation is in the spirit of Hall and Jorgenson (1967) where investment is assumed to reflect gradual adjustment of actual capital towards some desired level $\left(\mathrm{K}^{*}\right)$, which is a function of the expected future marginal productivity of capital and its marginal cost (where the later depends on the real interest rate and the real price of capital equipment):

$$
I=\lambda^{\prime}\left(K^{*}\left(P^{e}, r, P_{K}\right)-K_{t-1}\right)+d e p^{*} K_{t-1}
$$

Also Mansfield (1962) uses a similar capacity equation applied to the variation in rates of firms entering or exiting an industry. Gaskins (1971) uses Mansfield's specification to capture changes in capacity in a leader-followers oligopoly model.
} 
simulation experiment below, considers a $20 \%$ one-time increase in demand. We experiment with the value for $\lambda$, given our assumed price elasticity of resource demand of unity, to find a value that results in capacity rising to meet this $20 \%$ increase in demand in five to seven years. As mentioned above, Radetzki et al. (2008) use a simple model to analyze the boom in the mineral markets in the early 2000s and assume that "it takes five years following an investment decision for new capacity to come on stream" (p.124).$^{18}$ They argue that the adjustment period could well be longer in the current economic and regulatory environment.

Combining equations $(0.0)$ to $(0.0)$ yields a dynamic mineral supply curve that depends critically on the evolution of production capacity, which in turn depends on expected future prices:

$$
R_{t}^{S}=A\left[1+g_{t-1}+\lambda\left(\ln \left(\gamma P_{R, t-1}+(1-\gamma) P_{R, t+1}\right)-\ln M C\right)\right] K_{t-1}
$$

Although our mineral supply equation allows for a blend of model-consistent forward-looking and backward-looking price expectations, it does ignore some potentially important considerations: (1) the lumpiness of capital investment in large-scale mining projects, (2) the effect of price volatility in delaying investments with a very long life (due to the option value of waiting), (3) adjustment costs where it is more expensive to adjust the capital stock quickly, (4) investment irreversibility (or at least the asymmetric costs of increasing vs. decreasing investment).

\footnotetext{
${ }^{18}$ Note that high price and business cycle uncertainty coupled with the large capital costs and irreversibility of mineral projects will often make it optimal for firms to delay commitment to capacity expansion projects. However, some authors (Cairns 2010) believe that investment in capacity can take several years. Indeed, when applied to the oil market, some of the reasons for the delay are: (i) large sunk cost in transportation and refining, (ii) difficulty to coordinate the different types of investment, (iii) volatility and uncertainty in the market, and (iv) the investment budget of National Oil Companies ( NOCs ) and International Oil Companies ( IOCs ) not being aligned, while the NOCs control the majority of the market for oil.
} 
Ingredient \#6: The relative price of mineral resources assumed to adjust each period to clear the global market

$$
R^{S}=R^{D}
$$

This simple specification of market equilibrium ignores any role for inventories or gradual price adjustment (due to producer pricing, say). We believe that inventories play a large role when studying short-term business cycle fluctuations in some mineral prices, but should be less important in our effort to model longer-period super cycles. Pricing behavior varies widely across minerals depending on whether: (i) they are traded on formal exchanges (such as the LME, NYMEX, etc.), (ii) periodic bilateral price negotiations occur between producers and purchasers (as with iron ore), or (iii) producer pricing is the norm (industrial minerals such as talc, borax, rare earths, etc.).

\section{Simulations and Discussion}

A number of simulation exercises are now carried out to explore the implications of our model, to better understand its dynamic properties, and to determine whether it is capable of producing super cycles in mineral prices. Simulation $\# 1$ considers a one-time jump in real GDP in order to show that the chosen value of the speed of adjustment $\lambda$ (along with the short-run mineral supply and demand elasticities) imply capacity adjustment of about five years. Simulation \#2 simulates a gradual transition from stagnation to economic growth with structural transformation along the way to see if the dynamics of price adjustment yield super cycles.

Appendix B contains two other simulations: (i) a gradual transition from stagnation to growth without structural transformation and (ii) an instant jump in the GDP growth rate without structural transformation. Neither of these scenarios produces super cycles. Appendix C generalizes the model to include two regions at different development phases. 


\section{Simulation \#1: An Unanticipated One-Time Increase in Real GDP}

To eliminate the effect of arbitrary initial conditions, we first solve our model for a baseline scenario where there is no growth per capita income or population, and hence no change in $I O U$. The LR equilibrium values for all endogenous variables are then used as the initial conditions for all subsequent simulations. Simulation \#1 simulates an unanticipated one-time jump in real $G D P$ with no change in intensity of use. We experimented with the speed of adjustment parameter in the investment equation in order to produce results consistent with the common presumption that it takes about five years following an investment decision to bring marginal capacity on stream in the mineral sector. Figure 8 compares the results of a one-time unanticipated $20 \%$ level-shift in demand in the year 1880 relative to the baseline. This shift in demand causes a sharp increase in mineral price relative to marginal cost, which in turn sets in motion a gradual increase in mineral supply until the price returns to marginal cost. The speed of adjustment $\lambda$ on the supply side in (0.1) and the short run price elasticity on the demand side determine the time needed for the supply and the price to return to the LR equilibrium. Assuming an inelastic SR price elasticity of mineral demand, $\varepsilon_{P}=-0.2$, the speed of adjustment needed to produce full capacity adjustment to the $20 \%$ demand shock within $5-7$ years is roughly $\lambda=0.1$. The key parameter values used in the simulations that follow are summarized in Table 1. 
Table 1: Simulation 1 and 2 Parameter Values.

\begin{tabular}{ccccccc}
\hline \hline$\alpha_{A}$ & $\alpha_{M}$ & $\alpha_{S}$ & $\varepsilon_{P}$ & $\varepsilon_{y}$ & $\lambda$ & $\gamma$ \\
\hline 0.05 & 0.25 & 0.05 & -0.20 & 1.00 & 0.10 & 0.50
\end{tabular}

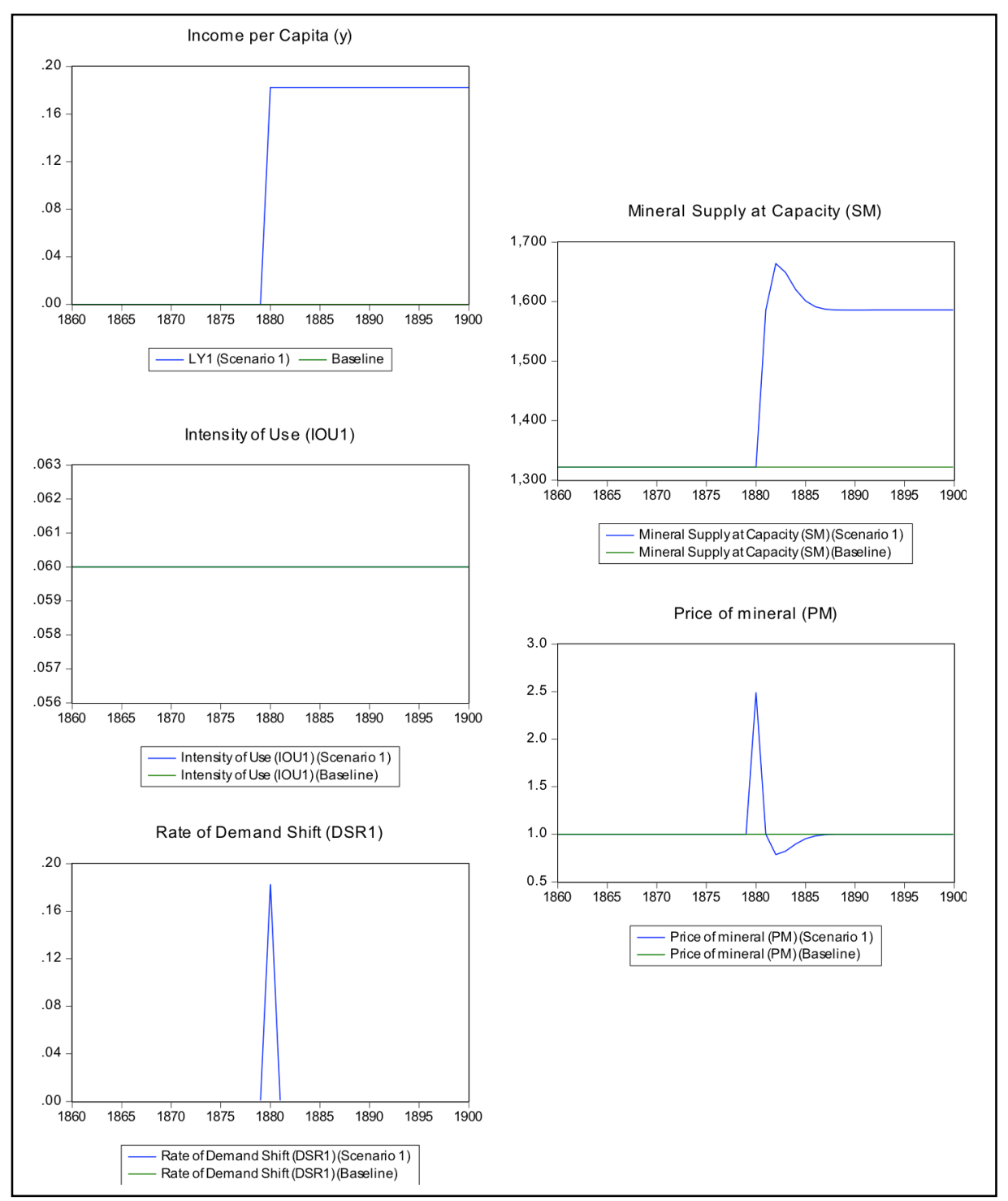

Figure 8 : Baseline scenario and simulation 1 . The baseline scenario represents the LR equilibrium. The parameter values given in Table 1 are used and the model is solved to converge to LR equilibrium before the period of interest. In the baseline scenario, the income level per capita and the intensity of use are kept constant. As the left panels show, there is no change in the income per capita growth rate (just a one-time $20 \%$ level shift) or the intensity of use. Hence, the rate of demand shift is transitory, as the level of demand jumps permanently to a higher level. There effects on mineral supply and the underlying real mineral price are shown in the right side panels. 
Simulation \#2: A Gradual Transition from Stagnation to Economic Growth with Structural

Transformation

Simulation 2 considers the gradual increase in the growth rate of GDP per capita shown in Figure 4, coupled with the structural transformation shown in Figure 9. These are the key drivers on the mineral demand side, namely income growth and the resulting changes in intensity of use. See the resulting time path of DSR in Figure 9 below. ${ }^{19}$ The supply reaches a balanced growth path again with a bump matching the peak in $I O U$. Under these conditions the price path tracks a super cycle with a peak coinciding with the peak of $D S R$ and occurring about 10 years before the peak in $I O U$ in this model. Initially it may seem counterintuitive that the peak of the super cycle does not match the peak in $I O U$, but it is the change in $I O U(I O U)$ not its level that drives the time path in prices. The change in $I O U$ is embedded in $(0.0)$, which explains why the SC peak coincides with the peak of $D S R$.

A comparison of the super cycles obtained using different price elasticities of demand, -0.20 and -1.0 respectively, is shown on Figure 10. (The speed of adjustment $\lambda$ was adjusted as the price elasticity of demand was changed in order to keep the adjustment for a $20 \%$ demand shock in the 5-7 year range.) The direct consequence of a less elastic demand is a price cycle with larger amplitude. Note that the length of the price cycle does not change, as it is directly related to the duration of the change in $I O U$.

${ }^{19}$ By simulating our model with different parameter values, it becomes clear that the overshooting adjustment path for capacity in the mineral sector corresponds with prices overshooting long-run marginal costs. The overshooting behavior depends on the speed of capacity adjustment and the weight on forward-looking (rather than backward-looking) price expectations. 


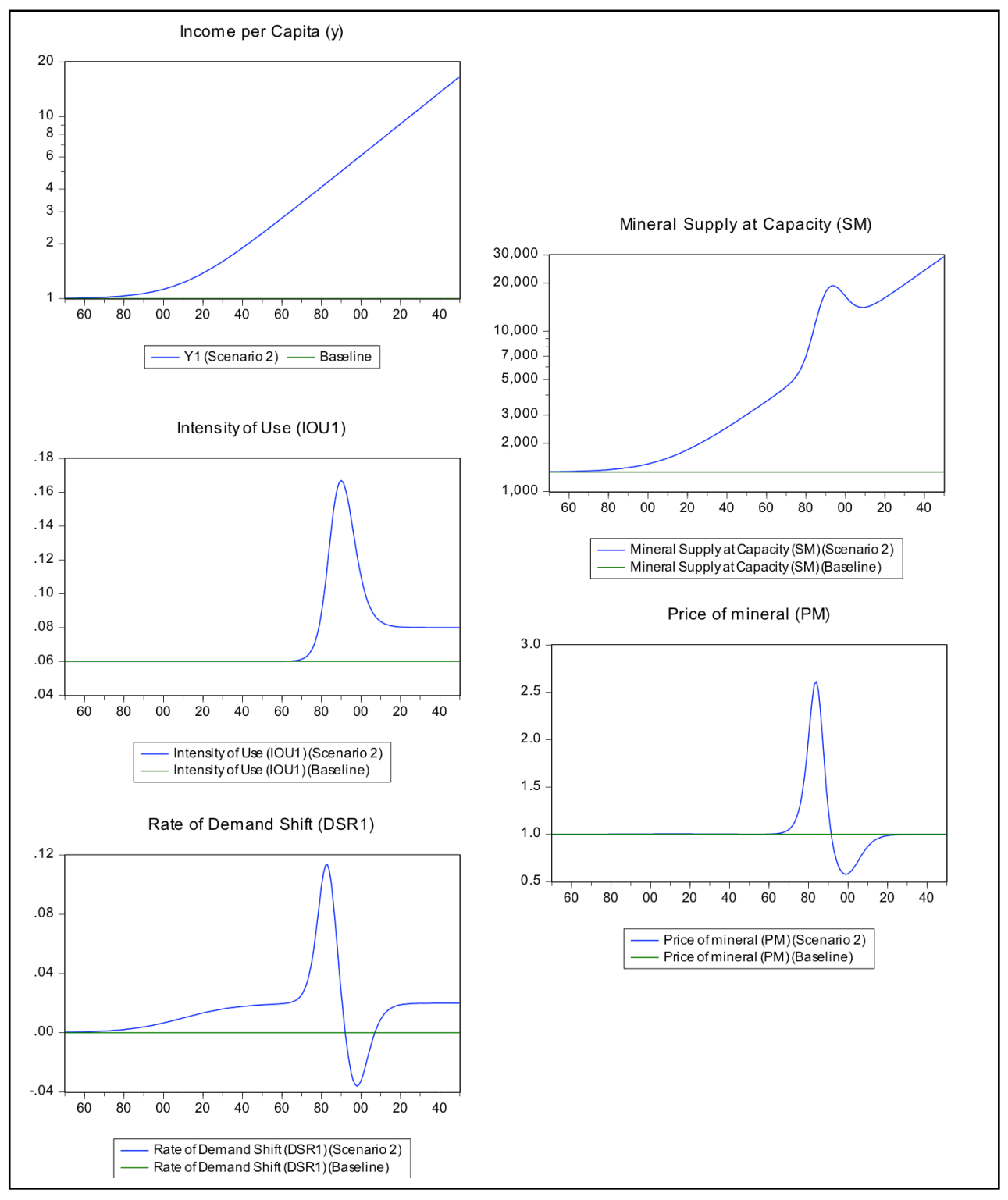

Figure 9: Simulation 2: a gradual transition from stagnation to economic growth with structural transformation. A super cycle is generated in this scenario. Notice that the peak in mineral price does not occur when the intensity of use is at its peak. It occurs at the peak of the demand shift for resources $(D S R)$. Note that the income per capita and the mineral supply are in log scale. 


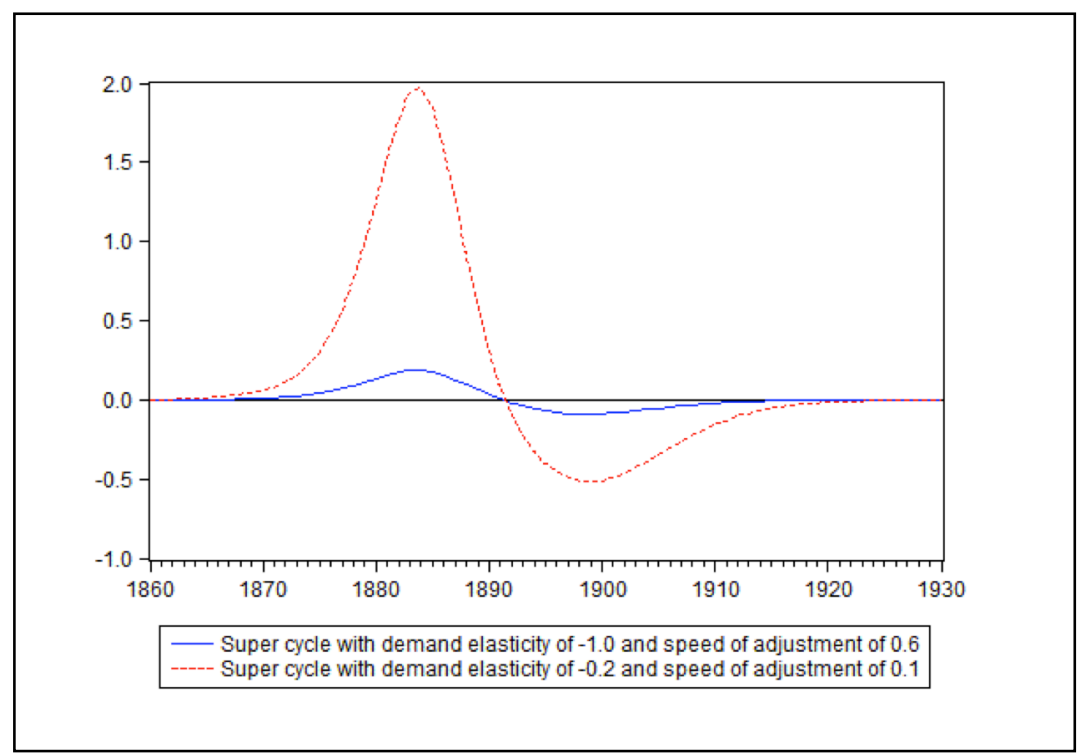

Figure 10: Comparison of the super cycles obtained using different pairs of elasticities of demand and speed of capacity adjustment, $(-0.2,0.1)$ and $(-1.0,0.6)$ respectively. Note that the lower demand elasticity produces a super cycle with larger amplitude. It does not, however, change the length of the super cycle, which is directly related to the duration of the change in IOU.

Examining the mineral price super cycle generated in Figure 9, one might ask: what is the relative role of the growth take off and the humped pattern in the aggregate intensity of mineral use (caused by structural transformation of the economy) in producing the super cycle. To address this question, Appendix B (Simulation \#3) considers the effects of a growth take off (from zero to $2 \%$ ) but with no change in the $I O U$. In this scenario the profit margin (price minus marginal cost) rises infinitesimally from zero to 0.003 over the ensuing century in order to bring about capacity expansion along the balanced growth path that equals the growth in demand of 2 percent. One can infer by comparing this scenario to the 'growth with structural transformation' case above, therefore, that the humped shape of the aggregate $I O U$ as per capita income rises is an essential ingredient in the generation of the super cycle behavior shown in Figure 9. 


\section{Summary and Conclusions}

This paper develops a stylized mineral commodity market model with (i) important distinctions between short-run and long-run mineral supply and (ii) a derived demand for minerals as intermediate goods in production sectors with differing intensities of use. The determinants of demand are the real price of minerals, income per capita, intensity of use (which varies with the level of economic development), and population. The spread between expected future mineral prices and their marginal cost affects production capacity gradually over time. One of our key questions is whether such a model is capable of producing a price cycle with super cycle amplitude and periodicity. With the collection of parameter values given in Table 1, the answer is 'yes.' The emergence of modern economic growth -- with the structural transformation that growth and economic development entails -- yields the long cycle shown in Figure 10. At their peak, mineral prices lay about $250 \%$ above their long-term trend and the cycle has a period of roughly 50 years. (This magnitude can be reduced by increasing the price elasticity of mineral demand, if one so desires.) In sum, our model appears to contain a combination of ingredients sufficient to generate super cycle behavior in mineral prices. It also makes clear that the structural transformation of the economy (with the humped pattern in the aggregate intensity of mineral use relative to per capita income) is an essential ingredient for producing super cycles using a demand-driven story like the one presented in this paper.

In our future research, a number of possible extensions to the prototype model will be considered. These include: (1) incorporating the population dynamics that accompany economic development (i.e. the so-called 'demographic transition'), (2) generalizing the model to include two or more countries rather than considering a global market, along the lines shown in 
Appendix C and (3) calibrating the model to match country or region-specific macrodevelopment data and one or more specific mineral markets (e.g., oil, copper, or coal).

Are there alternative explanations of possible super cycle behavior in mineral prices? John Tilton observes (in private correspondence) that he believes that long-term mineral price movements are primarily determined by movements in long-run marginal costs of production (which, in turn, reflect the opposing forces of ongoing depletion and technological change). By assuming that long-run marginal costs (MC) are constant, our model ignored this possibility. This raises the open question about whether long-cycles in $\mathrm{MC}$, rather than the gradual adjustment of supply capacity to surging demand, might produce super cycles in prices. One would, of course, have to come up with a theory as to why long (perhaps technology) cycles might occur (with similar timing) across a wide spectrum of mineral commodities. This is certainly worthy of future study. 


\section{REFERENCES}

Acemoglu, Daron. 2009. Introduction to Modern Economic Growth. Ch.20: Structural Change and Economic Growth. Princeton NJ: Princeton University Press.

Adelman, Irma. 1965. "Long Cycles: Fact or Artifact?" American Economic Review 55, 3, 44463.

Berg, Andrew, Philippe Karam, and Douglas Laxton. 2006a."A Practical Model-Based Approach to Monetary Policy Analysis - Overview." IMF Working Paper 02/080.

Berg, Andrew, Philippe Karam, and Douglas Laxton. 2006b."Practical Model-Based Monetary Policy Analysis: A How-to Guide." IMF Working Paper 06/081.

Cairns, Robert D, and Calfucura, Enrique. 2010. "OPEC : Market Failure or Power Failure ?" 22: McGill University, Montreal QC Canada.

Cuddington, John, and Daniel Jerrett. 2008. "Super Cycles in Real Metals Prices?" IMF Staff Papers 55, 4, 541-65.

Dahl, Carol A. and Thomas Duggan. 1996. "U. S. Energy Product Supply Elasticities: A Survey and Application to the U.S. Oil Market," Resource and Energy Economics 18, 243-263.

Dahl, Carol A. 1994. "A Survey of Energy Demand Elasticities for the Developing World," Journal of Energy and Development 18, 1, 1-48.

Fisher, Franklin M., Paul H. Cootner, and Martin Neil Baily. 1972. "An Econometric Model of the World Copper Industry." The Bell Journal of Economics and Management Science $3,2,568-609$.

Galor, Oded. 2011. Unified Growth Theory. Princeton University Press.

Gaskins, Darius W, Jr. 1971. "Dynamic Limit Pricing: Optimal Pricing under Threat of Entry." Journal of Economic Theory 3, 3, 306-22.

Heap, Alan. 2005. "China - The Engine of a Commodities Super Cycle." Equities Research: Global. New York City: Citigroup Smith Barney.

Jerrett, Daniel. 2010. "Trends and Cycles in Metals Prices." PhD Dissertation (Mineral and Energy Economics), Colorado School of Mines.

Jerrett, Daniel, and John T. Cuddington. 2008. "Broadening the Statistical Search for Metal Price Super Cycles to Steel and Related Metals." Resources Policy 33, 4, 188-95.

Krichene, Noureddine. 2002. "World Crude Oil and Natural Gas: A Demand and Supply Model,” Energy Economics 24, 557-576. 
Maddison, Angus. 2009. "Statistics on World Population, GDP and Per Capita GDP, 1-2006 AD." http://www.ggdc.net/maddison/.

Mansfield, Edwin. 1962. "Entry, Gibrat's Law, Innovation, and the Growth of Firms." American Economic Review 52, 5, 1023-51.

Radetzki, Marian, Roderick G. Eggert, Gustavo Lagos, Marcos Lima, and John E. Tilton. 2008. "The Boom in Mineral Markets: How Long Might It Last?" Resources Policy 33, 3, 125 28.

Radetzki, Marian. 2008. A Handbook of Primary Commodities in the Global Economy. Cambridge University Press, UK.

Rogers, Jim. 2004. Hot Commodities: How Anyone Can Invest and Profitably in the World's Best Market. Random House.

Tilton, John E. 2003. On Borrowed Time? Assessing the Threat of Mineral Depletion. Washington, DC: Resources for the Future.

Tilton, John E. 2006. "Understanding Cyclical and Secular Trends in Metal Prices." Mine Management Handbook. Australasian Institute of Mining and Metallurgy, Carlton, Victoria.

Tilton, John E. 2006. "Outlook for Copper Prices-Up or Down?" Mining Engineering (August), 16-20.

Warell, Linda Olsson, Anna. 2009. "Trends and Developments in the Intensity of Steel Use: An Econometric Analysis" in Securing the Future and 8th ICARD, 1-10. Skellefteå, Sweden.

Zellou, Abdel, and John T. Cuddington. 2012 (forthcoming). "Is There Evidence of Super Cycles in Oil Prices?" in SPE Economics and Management. 


\section{APPENDIX A: The Logistic Function and Intensity of Use}

Wikipedia's entry under 'logistic function' notes that an early use was in the study of population growth. It has proved to be very handy indeed: "The logistic function finds application in a range of fields including artificial neural networks, biology, biomathematics, demography, economics, chemistry, mathematical psychology, probability, sociology, political science, and statistics." It is used in this paper to characterize (i) the time path of per capita economic growth as a country emerges from Malthusian stagnation notes and (ii) the evolution of final goods expenditure shares during the development process.

The general formula of the logistic function applied to expenditure shares is:

$$
S_{i}=S_{i, 0}+\frac{S_{i, T}-S_{i, 0}}{1+e^{\left[-\gamma_{i}\left(\ln y-\ln y_{i}\right)\right]}}
$$

where $S_{i}$ represents the expenditure share in sector $i \forall i=A, M, S$ for agriculture, manufacturing and services. The initial value is $S_{i, 0}$. The specified long-run share is $S_{i, T}$, which may be higher or lower than the initial value depending on whether one wants a rising or falling share over time. The parameter $\gamma_{i}$ affects the speed of adjustment from the initial share to the terminal share as the $\log$ of per capita income $(\ln y)$ approaches and then surpasses a specified value $\left(\ln y_{i}\right)$. The latter value determines the inflection point in the logistic S-curve. ${ }^{20}$ We assume that $\ln y_{A}<\ln y_{S}$, so that the inflection point in the agricultural share comes at a lower level of per capita income and hence earlier in time than the inflection point in the service share.

The following characteristics can be drawn from this logistic function:

\footnotetext{
${ }^{20}$ Note that this expenditure system collapses to the simply homothetic Cobb-Douglas case when there is no change in the shares over time. Note that we ignore any price effects on expenditure shares, unlike, say, the translog specification.
} 
- The resource share is limited by initial and terminal bounds $S_{i, 0}, S_{i, T}$.

- Since the logistic function is symmetrical with respect to the inflexion point, it is easy to determine the share value at that point, being $S_{i}=S_{i 0}+\frac{S_{i, T}-S_{i, 0}}{2}$. Hence $\ln y$ is calculated by plugging in that value of the share into the logistic function. The inflexion point has then the following coordinates: $\ln y=\ln y_{i}$ and $S_{i}=S_{i 0}+\frac{S_{i, T}-S_{i, 0}}{2}$.

- The slope at the inflexion point equals:

$$
\left.\frac{d S_{i}}{d \ln y}\right|_{\ln y=\ln y_{i}}=\left.\frac{\gamma_{i} *\left(S_{i, T}-S_{i, 0}\right) * e^{\left[-\gamma_{i}\left(\ln y-\ln y_{i}\right)\right]}}{\left(1+e^{\left[-\gamma_{i}\left(\ln y-\ln y_{i}\right)\right]}\right)^{2}}\right|_{y=B}=\frac{\gamma_{i} *\left(S_{i, T}-S_{i, 0}\right)}{4}
$$

Since the parameter difference $S_{i, T}-S_{i, 0}$ is directly related to the change in the expenditure share, the slope at the inflexion point can be changed by altering $\gamma_{i}$.

This function has the following shape if we assume that the parameter $S_{i, T}-S_{i, 0}>0$.

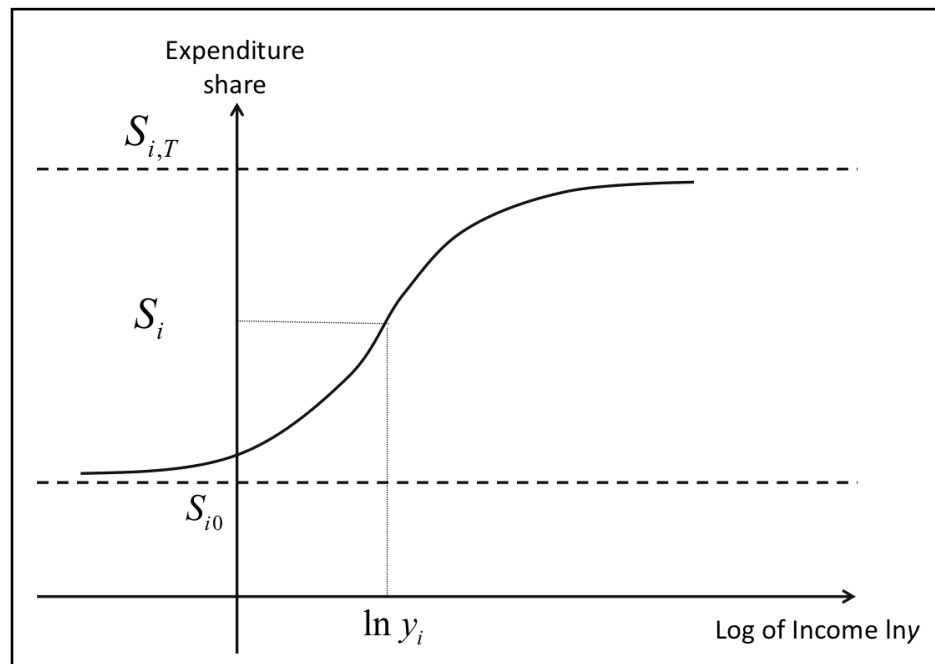

Figure 11: Logistic function applied to expenditure shares. 
When applied to the growth rate in per capita income, the logistic function can be tailored and written as:

$$
\text { growth rate }=D+\frac{C}{1+e^{[A(T I M E-B)]}}
$$

with parameter values of $\mathrm{D}=0, \mathrm{C}=.02, \mathrm{~B}=1810$ and $\mathrm{A}=0.07$. This yields the following: (1) an initial growth rate of zero, (2) a cumulative change in the growth rate of $2 \%$, and (3) a transition phase is centered at year 1810 (the inflection point in the logistic function), with the bulk of the transition occurring between 1750 and 1870, corresponding to the Post-Malthusian Regime (Figure 12).

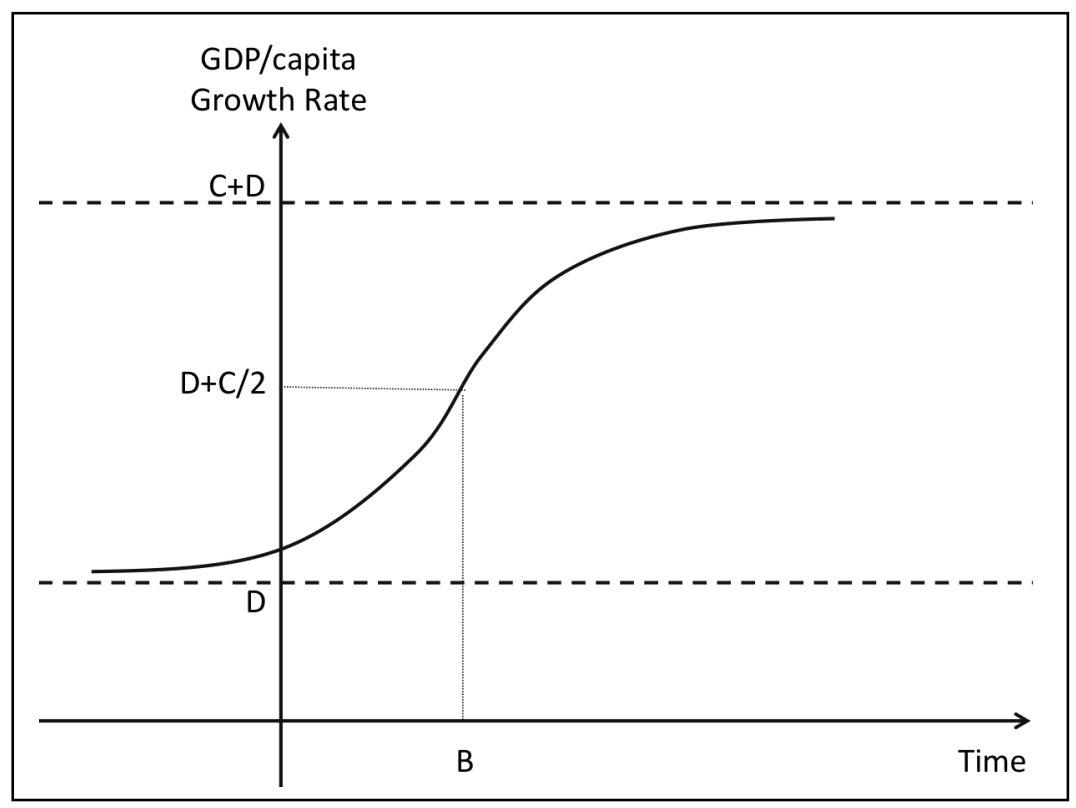

Figure 12: Logistic function used to generate the growth rate per capita according to Galor's unified growth theory and actual US output per capita growth rate. D represents the lower bound of the growth rate. $\mathrm{D}=0 \%$ in this case, corresponding to the Malthusian Epoch defined by Galor. $\mathrm{C}$ represents the upper bound with a value of $2 \%$ corresponding to the average growth rate during the modern growth regime. And $\mathrm{B}$ is the inflexion point during the transition period, namely the Post-Malthusian regime $(\mathrm{B}=1810)$. 


\section{APPENDIX B: Other Single-Region Simulations}

Simulation \#3: A Gradual Transition from Stagnation to Growth without Structural

$\underline{\text { Transformation }}$

In this simulation, the time path of per capita income follows that used in Simulation \#2 in Section 2.1 and displayed in Figure 4. Intensity of use (IOU), on the other hand, is held constant. That is, there is no structural transformation. Will a super cycle emerge in this situation?

Figure 13 displays the results of the simulation. Under this scenario, the growth rate of income per capita follows the path in the panel on the upper left corner. Since there is no change in the structural transformation of the economy, the intensity of use stays constant. The evolution in economic growth implies that the demand curve shifts outward at a rate that begins at zero percent and then accelerates, then decelerates, until it finds a steady-state rate of two percent. Supply 'runs to catch up,' ultimately reaching the balanced growth path at a rate of two percent. In this scenario the profit margin (price minus marginal cost) need only rise infinitesimally from zero to 0.003 over the ensuing century in order to bring about capacity expansion along the balanced growth path that equals the growth in demand of 2 percent. Interestingly, there is no super cycle in mineral prices under this scenario of gradual transition from stagnation to growth without structural transformation.

One can infer by comparing this scenario to the 'growth with structural transformation' case above, therefore, that the humped shape of the aggregate $I O U$ as per capita income rises is an essential ingredient in the generation of the super cycle behavior shown in Figure 9. 


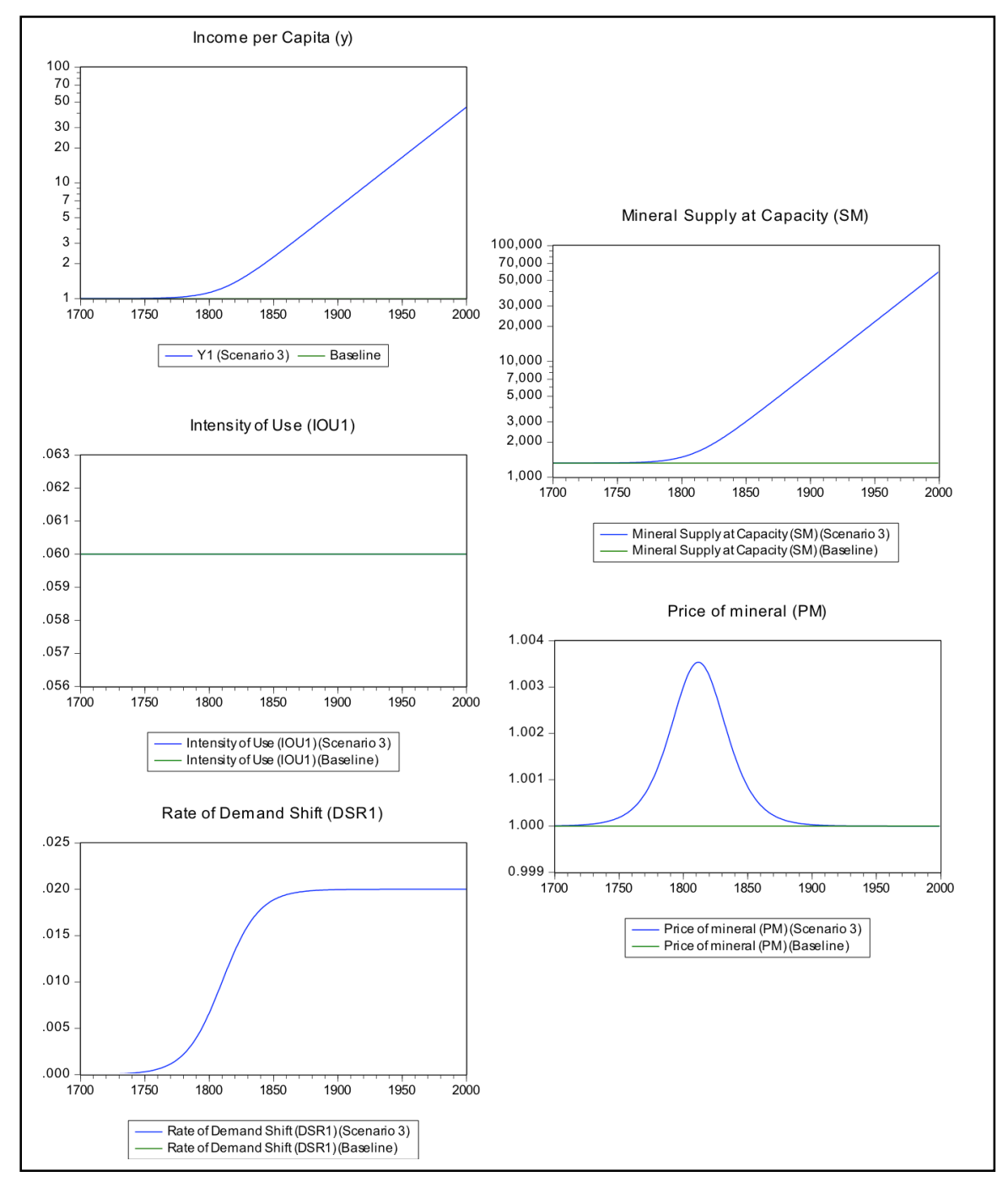

Figure 13: Simulation 3 considers a gradual transition from stagnation to growth, but without structural transformation. Under this scenario, the growth rate of income per capita follows the path in the panel on the upper left corner. Since there is no change in the structural transformation of the economy, the intensity of use stays constant. Because of the steady-state growth rate of two percent, demand and hence supply ultimately grows at two percent, as shown in the top left panel. The price of minerals reaches a new steady-state equilibrium level (not growth rate) under these conditions. Note that the income per capita and the mineral supply are in log scale. There is no super cycle in mineral prices under this scenario. 
Simulation \#4: An Instant Jump in Growth Rate from 0\% to 2\% without Structural

Transformation

Under this simulation the growth rate jumps instantly from zero to two percent in 1880

(Figure 14). The growth rate of income per capita follows the path in the panel on the upper left corner. Since there is no change in the structural transformation of the economy, the intensity of use stays constant. Because of the jump to a positive growth rate in income per capita, and therefore an ongoing shift in demand, prices start to rise and supply ultimately responds as capacity additions occur. Note that along the new balanced growth path, price must ultimately settle back at the level of marginal cost. 


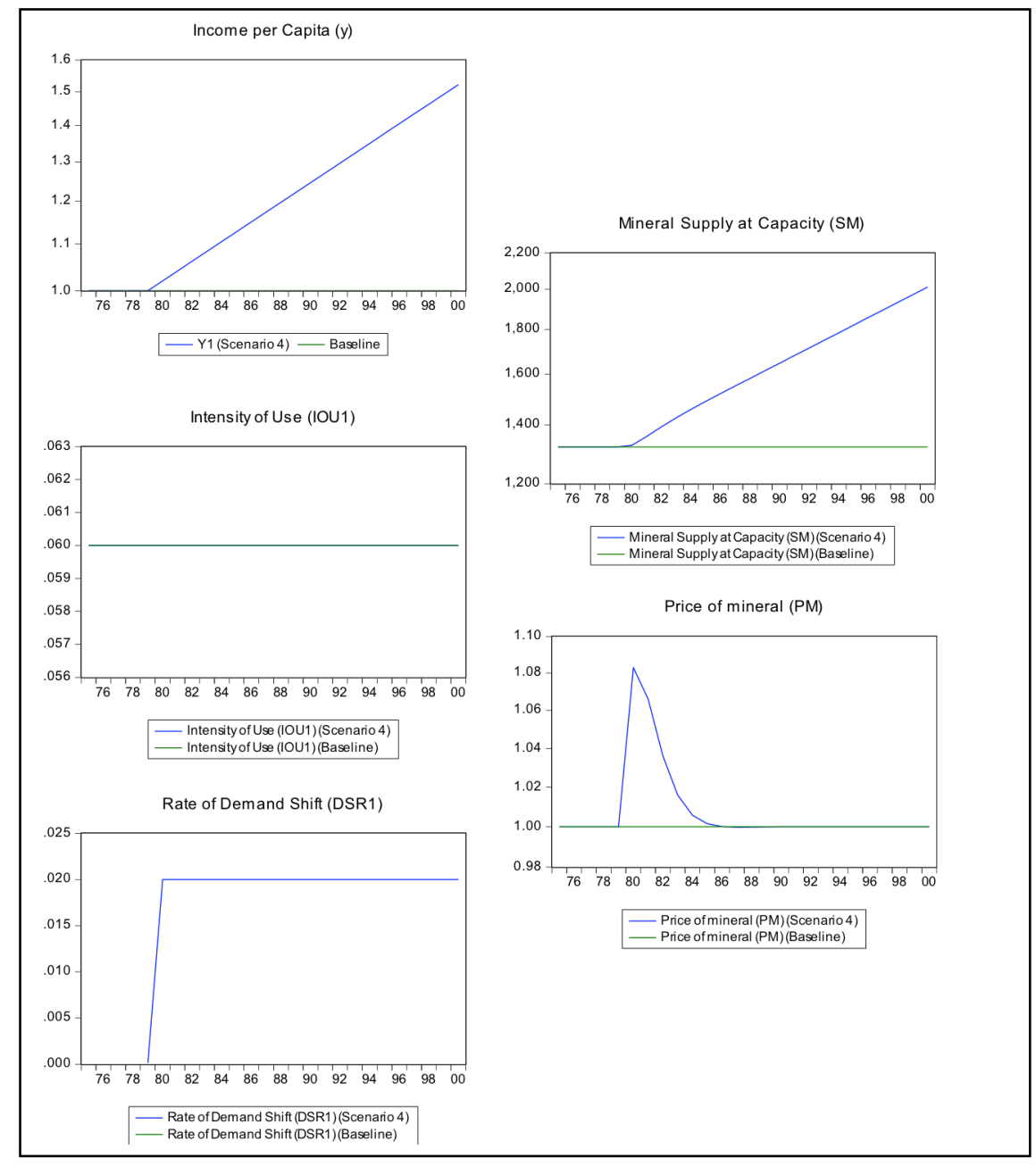

Figure 14: An Instant Jump in Growth Rate from 0\% to 2\% without Structural Transformation. Under this scenario, the growth rate of income per capita follows the path in the panel on the upper left corner. Since there is no change in the structural transformation of the economy, the intensity of use stays constant. Because of the jump to a positive growth rate in income per capita, and therefore an ongoing shift in demand, prices start to rise and supply ultimately responds as capacity additions occur. Along the new balanced growth path, price must settle above marginal cost with a profit margin sufficient to produce the needed ongoing growth rate in productive capacity. Note that the income per capita and the mineral supply are in log scale. There is no super cycle in mineral prices under this scenario. 


\section{APPENDIX C: Adding a Second Country or Region with Structural Transformation to Get a Second Super Cycle (Simulation \#5)}

The purpose of our model is to study the circumstances under which a surge in mineral demand associated with the structural transformation of a major country or region in the global economy could cause a super cycle in mineral prices. Presumably as different regions reach the 'take off' phase of their development, new super cycles will occur.

Logical extension of our single super cycle analysis in the text suggests past super cycles are the result of different regions entering the era of modern economic growth in stages (Western Europe, the 'Western Offshoots' (Canada, US, Australia) [as economic historian Angus Maddison calls them], Japan and Asian Tigers, and now China. This Appendix extends our simulation model to allow for a second large region. The simulation model in the text considered a global economy with population size one hundred to enter the epoch of modern economic growth. Here we add a second emerging country or region. One hundred and sixty years later, this second country with population size nine hundred enters the modern growth era. The result is two super cycles (Figure 15). Our incorporation of a second super cycle, and the experimentation that this entailed, suggests that successive regions that enter the development era must by larger and larger to produce super cycles of roughly similar amplitude. The relative impact of equal-sized newcomer nations on the global resource markets becomes smaller and smaller because their incremental effect on global GDP is proportionately smaller with each new entrant. 


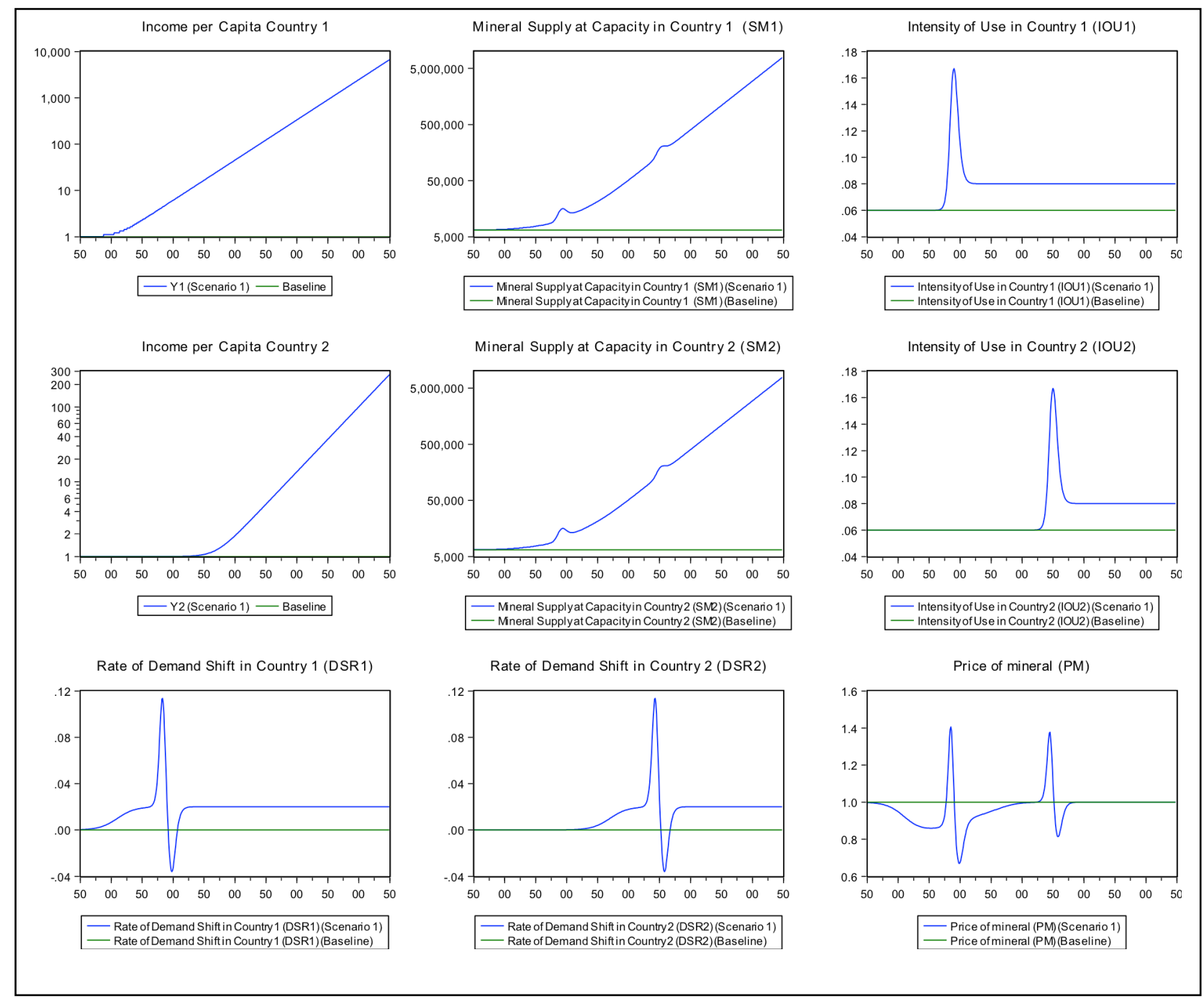

Figure 15: A Second Country or Region with Structural Transformation: Two Super Cycles. Under this scenario, our simulation model allows for an initial country with population size one hundred to enter the epoch of modern economic growth. One hundred and sixty years later, a second country of population size nine hundred enters the modern growth era. The result is two super cycles. 